\title{
Telomere length and radiosensitivity in human fibroblast clones immortalized by ectopic telomerase expression
}

\author{
SAMANTHA ZONGARO $^{1}$, ANNALISA VERRI $^{1,3}$, ELENA GIULOTTO ${ }^{2}$ and CHIARA MONDELLO ${ }^{1}$ \\ ${ }^{1}$ Istituto di Genetica Molecolare, CNR, Via Abbiategrasso 207; ${ }^{2}$ Dipartimento di Genetica e Microbiologia \\ ‘Adriano Buzzati Traverso', Università di Pavia, Via Ferrata 1, 27100 Pavia, Italy
}

Received November 12, 2007; Accepted February 5, 2008

\begin{abstract}
Telomeres, the ends of eukaryotic chromosomes, have a variable length among individuals and cell types. While studies in telomerase-deficient mice and cells showed an inverse correlation between telomere length and radiosensitivity, it is less clear whether this remains true in telomerase-proficient cells. To gain insight into this topic, we studied radiosensitivity in three telomerase immortalized fibroblast clones derived from the same cell line and characterized by different telomere length. In two clones, cen3tel4 and cen3te15, the mean terminal restriction fragment length was $\sim 13$ and $10 \mathrm{~kb}$, respectively and in the third clone, cen3pci16, it was $\sim 4 \mathrm{~kb}$, which is lower than in senescent fibroblasts. To test radiosensitivity, we determined survival to $\gamma$-rays and the induction of chromosomal aberrations after irradiation. Neither the $\mathrm{LD}_{50}$, the $\gamma$-ray dose that reduces survival to $50 \%$, nor the frequency of aberrations detected in the three cell lines showed an inverse correlation with telomere length. In particular, the cen 3 pci16 cells, which have very short telomeres, did not show a higher sensitivity to irradiation or a greater frequency of chromosomal abnormalities compared to the other two cell lines. Our results suggest that, in the presence of telomerase activity, short telomeres are stabilized and do not cause an increase in radiosensitivity.
\end{abstract}

\section{Introduction}

Stretches of short tandem repeats, associated with specific proteins, constitute telomeres, the ends of eukaryotic chromosomes (1). In humans, telomeres are formed by the TTAGGG hexanucleotide, which is repeated for $\sim 6-20 \mathrm{~kb}$, depending on tissue and cell reproductive history. Telomere length homeostasis is mainly guaranteed by telomerase, the ribonucleoprotein that adds telomeric repeats to chromosome

Correspondence to: Dr Chiara Mondello, Istituto di Genetica Molecolare, CNR, Via Abbiategrasso 207, 27100 Pavia, Italy

E-mail: mondello@igm.cnr.it

Present address: ${ }^{3}$ Sezione di Genetica Molecolare, Centro Diagnostico Italiano, Via S. Bon 20, Milano, Italy

Key words: telomere, telomerase, human fibroblasts, immortalization, radiosensitivity ends, bypassing the inability of DNA polymerases to replicate the 3 ' end of linear DNA molecules (2). Human telomerase catalytic activity is assured by a protein complex formed by a catalytic subunit (hTERT), which functions as a reverse transcriptase, an RNA component (hTERC), which contains the template for the synthesis of telomeric repeats, and the dyskerin protein (3).

In human somatic cells, telomerase activity is not sufficient in elongating telomeres, which thus shorten at each cell division (4). When telomeres reach a critical length, chromosome ends can be recognized as DNA double-strand breaks (DSBs) and trigger a replicative arrest, known as cellular senescence (5). Senescent cells remain metabolically active, although they are not able to divide. In different types of somatic cells, including fibroblasts, cellular senescence can be bypassed by ectopically expressing the telomerase catalytic subunit. Fibroblasts acquiring telomerase activity stabilize telomeres, become immortal and can proliferate indefinitely (6).

A hallmark of cells approaching senescence is the presence of dicentric chromosomes, derived from two chromosomes fused at the telomeres $(7,8)$. Telomere shortening can lead to the genesis of dysfunctional telomeres, which activate the nonhomologous end-joining (NHEJ) pathway and are joined together (9). In mammalian cells, NHEJ is the main mechanism deputed in the repair of DNA DSBs, it accomplishes this task together with the homologous recombination pathway (10). Notably, although one of the key functions of telomeres is to prevent the activity of the repair machinery on chromosome ends, several DSB repair proteins interact with telomeres and are important for their proper functionality (11).

Besides the sharing of factors between telomeres and DSB repair systems, evidence has been reported that telomere length and telomerase expression can influence the sensitivity of cells and organisms to DSB inducers, such as ionizing radiations (IR) (12). Hypersensitivity to IR has been clearly shown in late generation telomerase deficient $\mathrm{hTERC^{-/ }}$ mice and in cells derived from them (13-15), while in cells expressing telomerase, the inverse correlation between telomere length and radiosensitivity is still an open question. To investigate the relationship between telomere length, telomerase and radiation sensitivity, we analyzed the response to $\gamma$-rays, in terms of survival and of chromosomal damage, in three clones characterized by different telomere lengths, which were obtained from a fibroblast cell line immortalized by ectopic telomerase expression. 


\section{Materials and methods}

Primary cen 3 fibroblasts were obtained from unexposed skin of a centenarian individual and were described by Mondello et al $(16,17)$. The hTERT containing constructs pCIneohTERT and pBABEpuro-hTERT were a generous gift from R. Weinberg (Whitehead Institute for Biomedical Research, Cambridge, MA). Cen3pci16 and cen3pci3 cells derive from two clones obtained after transfection of the cen 3 primary fibroblasts with the pCIneo-hTERT plasmid. Transfection was performed using the 'FuGENE 6 transfection reagent' (Boehringer, Mannheim); transfected cells were selected with neomycin $(200 \mu \mathrm{g} / \mathrm{ml})$. Cen3pci3 cells did not express hTERT (not shown) and entered senescence, slowing down growth rate and acquiring an enlarged and stellate morphology. The cen3tel4 and cen3tel5 clonal cell lines are subclones derived from the cen3tel polyclonal population, which was obtained by infection of cen3 fibroblasts with the pBABEpuro-hTERT retroviral vector (18). Cells were grown in DMEM supplemented with $10 \%$ fetal calf serum. Propagation of the clones, directly obtained after transfection or seeding of single cells from mass transduced cultures, was performed as follows: after isolation, clones were placed in a $1.6-\mathrm{cm}$ well. When cultures reached confluence, cells were transferred into a $2-\mathrm{cm}$ dish and then in a T25 flask. Confluent T25s contained $\sim 1 \times 10^{6}$ cells and therefore represented $\sim 20$ population doublings (PD) of the cell that gave rise to the clone. At this stage, cultures were divided 1 in 2 every time cells reached confluence and the number of PD was increased to 1 unit at each division.

Irradiation was carried out using a ${ }^{60} \mathrm{Co} \gamma$-ray source. Cells $\left(5 \times 10^{5}\right)$ from confluent cultures of each cell line were resuspended in $1 \mathrm{ml}$ of complete tissue culture medium, placed in 7-ml tubes (Bijou, Sterilin) and irradiated with different doses. After irradiation, cells were diluted and seeded in petri dishes. For survival curves, cells were seeded at a density of $2-2.5 \times 10^{3} / 10 \mathrm{~cm}$ dish. After two weeks at $37^{\circ} \mathrm{C}$, the plates, two for each dose, were rinsed with PBS, fixed with methanol, stained with Coomassie Brilliant Blue (1\% page blue in $50 \%$ methanol and $7.5 \%$ acetic acid) and the colonies with $>50$ cells were counted. For each dose, the percentage of surviving colonies in respect to those obtained in the control cells was calculated. For chromosome preparations, $5 \times 10^{4}$ irradiated cells and $4 \times 10^{4}$ control cells were distributed onto a microscope slide placed into a petri dish. After $48 \mathrm{~h}$ at $37^{\circ} \mathrm{C}$, nocodazole (Sigma) was added at a final concentration of $0.2 \mu \mathrm{g} / \mathrm{ml}$ and cells were further incubated for $3 \mathrm{~h}$ at $37^{\circ} \mathrm{C}$. Cells were then treated with $0.56 \% \mathrm{KCl}$ and fixed with methanol/acetic acid at 3:1 to obtain chromosome preparations.

Telomere length was analyzed by Southern blotting and telomerase activity was determined by a modification of the TRAP assay (19). The two methods were previously described by Mondello et al (18).

\section{Results and Discussion}

Cen3tel4 and cen3tel5 are clonal populations derived from cen3 primary fibroblasts infected with a retrovirus carrying the cDNA for hTERT. Cen3pci16 derives from a clone obtained from the same primary fibroblasts transfected with a plasmid

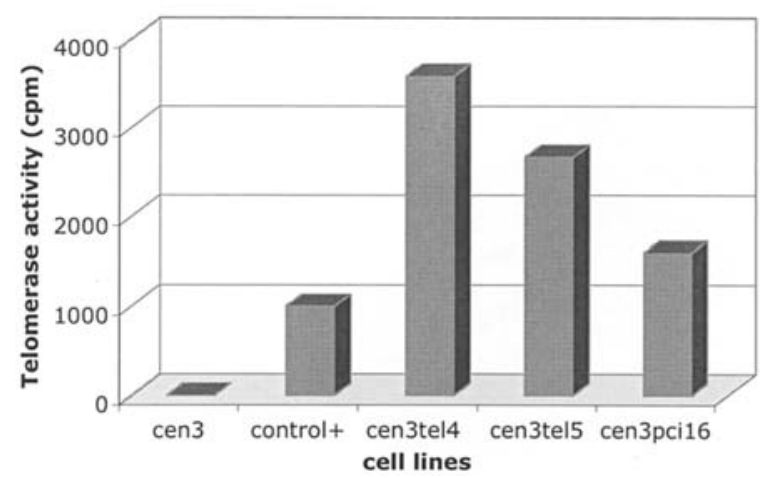

Figure 1. Telomerase activity in cen3tel4, cen3tel5 and cen3pci16 cells. Cell extracts $(0.5 \mu \mathrm{g})$ were incubated in the presence of a synthetic oligonucleotide that could be a substrate for the addition of telomeric repeats by telomerase. If telomerase activity was present in the extracts, the oligonucleotide was elongated and could work as a template in a subsequent PCR reaction. PCR was performed in the presence of ${ }^{3} \mathrm{H}$-labeled nucleotides and the formation of the amplification product was evidentiated by monitoring the incorporation of radioactivity in acid-precipitable DNA (counts per minutes: cpm). Cen3 primary fibroblasts were used as negative controls and a cell extract prepared from the positive control cells contained in the TRAPeze kit (Chemicon) were used as a positive control.

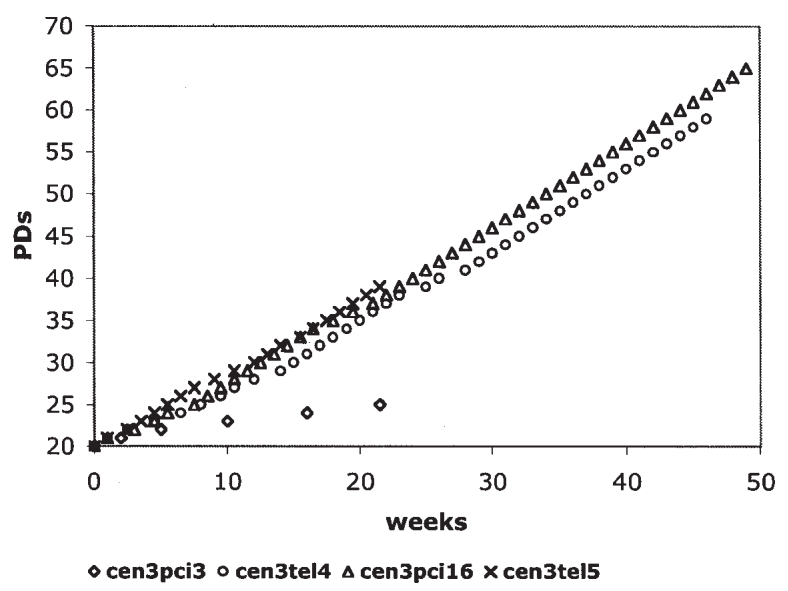

Figure 2. Growth curves of cen3te14, cen3te15 and cen3pci16 cells. Cen3te14, cen3te15 and cen3pci16 telomerase-positive cells showed a continuous growth. The growth curve of the cen3pci3 cells (see Materials and methods), which did not express hTERT (data not shown), is an example of the slowing down and then arrest of the growth characterizing senescent cells.

containing the hTERT cDNA. The three cell lines showed telomerase activity (Fig. 1) and bypassed cellular senescence (Fig. 2).

Telomere length analysis and radiosensitivity experiments were carried out using cen3tel 4 cells between PDs 46 and 59, cen3tel5 between PDs 36 and 47 and cen3pci16 between PDs 74 and 87 . The distribution of the Terminal Restriction Fragments (TRFs) was used as a measure of telomere length in the three cell lines. DNA samples prepared from each cell line at two different PDs were digested with RsaI and HinfI and hybridized to a probe for the telomeric repeat (TTAGGG)n. By this method, a smeared hybridization signal is obtained that reflects TRF heterogeneity in the cells. The signal intensity along each lane was quantified and the data were used to determine the mean TRF length. As shown in Fig. 3, the three 
Table I. Chromosomal aberrations in cen3tel4, cen3tel5 and cen3pci16 cells after irradiation with $\gamma$-rays.

\begin{tabular}{|c|c|c|c|c|c|c|c|c|c|}
\hline Cell line & $\gamma$-ray dose $(\mathrm{Gy})$ & N. mitoses & Aberrant mitoses $(\%)$ & Breaks & Dic & Fr & Rings & Others & Tot. aber. \\
\hline \multirow[t]{2}{*}{ Cen3tel4 } & 0 & 127 & 12.6 & 15.7 & 0.0 & 0.0 & 0.0 & 0.0 & 15.7 \\
\hline & 2 & 93 & 59.1 & 26.9 & 25.8 & 28.8 & 5.4 & 6.4 & 93.3 \\
\hline \multirow[t]{2}{*}{ Cen3tel5 } & 0 & 43 & 4.6 & 4.6 & 0.0 & 0.0 & 0.0 & 0.0 & 4.6 \\
\hline & 2 & 59 & 52.5 & 23.7 & 37.2 & 25.4 & 1.7 & 1.7 & 91.5 \\
\hline \multirow[t]{2}{*}{ Cen3pci16 } & 0 & 49 & 14.3 & 8.2 & 2.0 & 0.0 & 0.0 & 0.0 & 10.2 \\
\hline & 2 & 61 & 49.2 & 31.1 & 21.3 & 24.6 & 6.5 & 0.0 & 83.8 \\
\hline
\end{tabular}

Breaks; Dic, dicentrics; Fr, fragments; rings; others and Tot. aber., total aberrations. All are reported as number/100 mitoses.

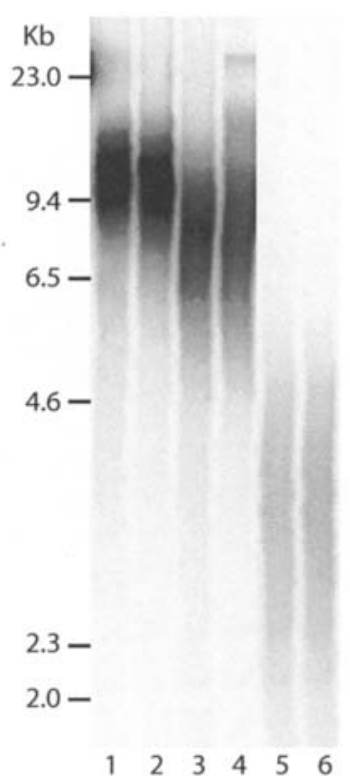

Figure 3. TRF distribution in cen3tel4, cen3tel5 and cen3pci16 cells at two different PDs. Lane 1, cen3tel4 PD 54; lane 2, cen3tel4 PD 58; lane 3, cen3tel5 PD 37; lane 4, cen3tel5 PD 46; lane 5, cen3pci16 PD 75 and lane 6, cen3pci16 PD 82

cell lines show different distributions of TRFs. Cen3tel4 is characterized by the longest telomeres, the average TRF length is $\sim 13 \mathrm{~kb}$ (Fig. 3, lanes 1 and 2). In cen3tel5, the mean TRF length is $\sim 10 \mathrm{~kb}$ (Fig. 3, lanes 3 and 4) and cen3pci16 presents the shortest telomeres, where the average TRF length is $\sim 4 \mathrm{~kb}$ (Fig. 3, lanes 5 and 6), lower than that detected in the cen3 primary fibroblasts at senescence $(\sim 6 \mathrm{~kb})(18)$. Despite the short telomeres, cen3pci16 cells showed a growth curve similar to that of the cen3tel4 and cen3tel5 cells (Fig. 2).

To test radiosensitivity, the cen 3 tel4, cen3tel5 and cen3pci16 cells were irradiated with $\gamma$-ray doses comprised between 1 and 6 Gy and plated at a low density. After 15 days, cells were fixed and the percentage of cells able to form colonies, relative to the un-irradiated controls, was determined. As shown in Fig. 4A, where survival curves are reported, cen 3 tel 5 cells are characterized by a radiosensitivity slightly higher than the cen3tel4 and cen3pci16 cells, which show similar levels of sensitivity (the $\gamma$-ray doses reducing survival to $50 \%, \mathrm{LD}_{50}$, were $\sim 1.4 \mathrm{~Gy}$ in cen3tel5, 2.6 Gy in cen3tel4 and $2.4 \mathrm{~Gy}$ in cen3pci16). Thus, in the three cell lines, we did
A

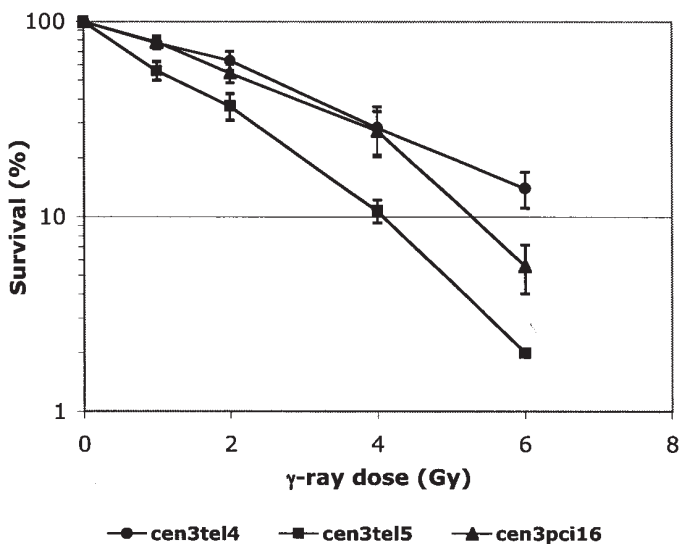

B

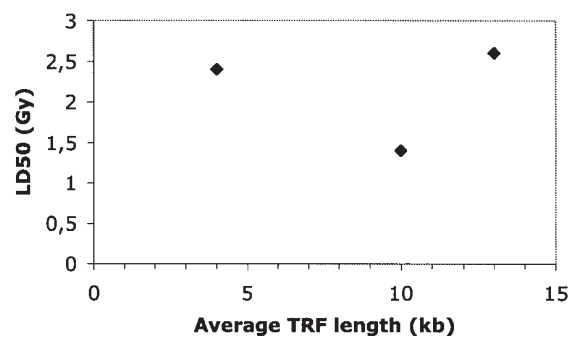

Figure 4. (A) Survival curves of cen3tel4, cen3tel5 and cen3pci16 cells after irradiation with $\gamma$-rays. Each survival value derives from the average among the values obtained in four independent experiments. The standard error bar is shown. (B) Average TRF length and $\mathrm{LD}_{50}$ in the three cell lines (from left to right, dots represent: cen3pci16, cen3tel5 and cen3tel4).

not find any relationship between telomere length and radiosensitivity (Fig. 4B). Cen3tel4 and cen3pci16 have a very different telomere length, though similar levels of radiosensitivity, whereas cen3tel5 has longer telomeres than cen3pci16, though is more sensitive to ionizing radiations.

We then analyzed chromosomal aberrations induced by $\gamma$-rays in the cen3tel4, cen3tel5 and cen3pci16 cells. In Giemsa-stained metaphases, we determined the frequency of breaks (chromosome and chromatid) and of structural chromosomal aberrations, such as chromosome fragments, 
dicentrics and rings. In the category called others, we included monocentric chromosomes clearly derived by a rearrangement (Table I). In the three cell lines, spontaneous chromosomal aberrations are almost exclusively chromosome breaks, which show a similar incidence in the cen3tel4 and cen3pci16 cells and lower levels in the cen3tel5 cells. After irradiation with a $2 \mathrm{~Gy}$ dose of $\gamma$-rays, the percentage of aberrant mitoses ranged from $49.2 \%$ in cen3pci16 to $59.1 \%$ in cen3tel 4 and the number of chromosomal aberrations/100 mitoses, from 83.3 in cen3pci16 to 93.3 in cen3tel4. Thus, as far as the induction of chromosomal aberrations is concerned, we did not find an inverse correlation between this parameter and telomere length in the three cell lines.

It is worthwhile underlining that, despite the presence of telomeres shorter than those present in senescent cells, in the un-irradiated cen 3 pci16 cells, we did not detect telomeric associations, which we actually observed in cen 3 primary fibroblasts approaching senescence (17). This observation indicates that, in the presence of telomerase activity, short telomeres are stabilized and are not prone to fusion, confirming the hypothesis that telomerase plays a role in the maintenance of the telomere structure (20).

A large body of evidence suggests that in primary cells, in which telomerase activity is insufficient in maintaining telomere length (21-24), or is completely absent (13-15), there is an inverse correlation between telomere length and radiosensitivity. In contrast, in mouse established cell lines, which express telomerase, this type of correlation has not been described (22). Recently, Sprung et al (25) studied two pairs of isogenic murine lymphoid cell lines characterized by different radiosensitivity and within each pair, by different telomere length. The authors showed that each member of a pair showed the same sensitivity to IR, independently of telomere length.

Our results obtained from isogenic human cell lines indicate that, in the presence of telomerase, radiosensitivity is independent of telomere length and that even telomeres shorter than those detected at senescence are not associated with an increased sensitivity to IR. Latre et al (15) showed that the higher frequency of chromosomal aberrations observed in late generation telomerase-deficient mice was due to the formation of a specific type of anomaly, in which a chromosome with short, dysfunctional telomeres, due to the lack of telomerase, joined to the end of a chromosome broken upon irradiation, giving rise to an unstable dicentric chromosome. In the cen3pci16 cells, the very short telomeres appear to be stable, they do not impair either cell growth or chromosomal stability and thus do not increase sensitivity to IR.

Several lines of evidence indicate that telomerase inhibition sensitizes human cancer cells to radiation (26-28). Our results suggest that even in tumors characterized by very short telomeres, telomerase inhibition can be required to increase sensitivity to radiotherapy.

\section{Acknowledgements}

We are very grateful to Professor A. Faucitano and Professor A. Buttafava (University of Pavia) for rendering available to us the $\gamma$-ray source and for taking care of irradiation. We acknowledge the following Institutions for the grants supporting our research: EU (FIGHT-CT 2002-217; F16R-CT-2003-508842), Italian Ministero dell'Università e della Ricerca (FIRB RBAU01ZB78) and Fondazione Cariplo (2006-0734).

\section{References}

1. Blackburn EH, Greider CW and Szostak JW: Telomeres and telomerase: the path from maize, Tetrahymena and yeast to human cancer and aging. Nat Med 12: 1133-1138, 2006.

2. Collins $\mathrm{K}$ : The biogenesis and regulation of telomerase holoenzymes. Nat Rev Mol Cell Biol 7: 484-494, 2006.

3. Cohen SB, Graham ME, Lovrecz GO, Bache N, Robinson PJ and Reddel RR: Protein composition of catalytically active human telomerase from immortal cells. Science 315: 1850-1853, 2007.

4. Harley CB: Telomere loss: mitotic clock or genetic time bomb? Mutat Res 256: 271-282, 1991.

5. Campisi J and d'Adda di Fagagna F: Cellular senescence: when bad things happen to good cells. Nat Rev Mol Cell Biol 8: 729-740, 2007.

6. Bodnar AG, Ouellette M, Frolkis M, Holt SE, Chiu CP, Morin GB, Harley CB, Shay JW, Lichtsteiner S and Wright WE: Extension of life-span by introduction of telomerase into normal human cells. Science 279: 349-352, 1998.

7. Mondello C, Riboni R, Casati A, Nardo T and Nuzzo F: Chromosomal instability and telomere length variations during the life span of human fibroblast clones. Exp Cell Res 236: 385-396, 1997.

8. Riboni R, Casati A, Nardo T, Zaccaro E, Ferretti L, Nuzzo F and Mondello C: Telomeric fusions in cultured human fibroblasts as a source of genomic instability. Cancer Genet Cytogenet 95: $130-136,1997$.

9. Riha K, Heacock ML and Shippen DE: The role of the nonhomologous end-joining DNA double-strand break repair pathway in telomere biology. Annu Rev Genet 40: 237-277, 2006.

10. O'Driscoll M and Jeggo PA: The role of double-strand break repair - insights from human genetics. Nat Rev Genet 7: 45-54, 2006.

11. Slijepcevic P: The role of DNA damage response proteins at telomeres - an 'integrative' model. DNA Repair (Amst) 5: 1299-1306, 2006.

12. Genesca A, Martin M, Latre L, Soler D, Pampalona J and Tusell L: Telomere dysfunction: a new player in radiation sensitivity. Bioessays 28: 1172-1180, 2006.

13. Goytisolo FA, Samper E, Martin-Caballero J, Finnon P, Herrera E, Flores JM, Bouffler SD and Blasco MA: Short telomeres result in organismal hypersensitivity to ionizing radiation in mammals. J Exp Med 192: 1625-1636, 2000.

14. Wong KK, Chang S, Weiler SR, Ganesan S, Chaudhuri J, Zhu C, Artandi SE, Rudolph KL, Gottlieb GJ, Chin L, Alt FW and DePinho RA: Telomere dysfunction impairs DNA repair and enhances sensitivity to ionizing radiation. Nat Genet 26: 85-88, 2000 .

15. Latre L, Tusell L, Martin M, Miro R, Egozcue J, Blasco MA and Genesca A: Shortened telomeres join to DNA breaks interfering with their correct repair. Exp Cell Res 287: 282-288, 2003.

16. Mondello C, Moralli D, Franceschi C and Nuzzo F: Occurrence and expansion of trisomy 7 in a fibroblast strain from a centenarian individual. Exp Gerontol 34: 715-719, 1999.

17. Mondello C, Petropoulou C, Monti D, Gonos ES, Franceschi C and Nuzzo F: Telomere length in fibroblasts and blood cells from healthy centenarians. Exp Cell Res 248: 234-242, 1999.

18. Mondello C, Chiesa M, Rebuzzini P, Zongaro S, Verri A, Colombo T, Giulotto E, D'Incalci M, Franceschi C and Nuzzo F: Karyotype instability and anchorage-independent growth in telomerase-immortalized fibroblasts from two centenarian individuals. Biochem Biophys Res Commun 308: 914-921, 2003.

19. Kim NW, Piatyszek MA, Prowse KR, Harley CB, West MD, Ho PL, Coviello GM, Wright WE, Weinrich SL and Shay JW: Specific association of human telomerase activity with immortal cells and cancer. Science 266: 2011-2015, 1994.

20. Blackburn EH: Switching and signaling at the telomere. Cell 106: 661-673, 2001.

21. Castella M, Puerto S, Creus A, Marcos R and Surralles J: Telomere length modulates human radiation sensitivity in vitro. Toxicol Lett 172: 29-36, 2007. 
22. McIlrath J, Bouffler SD, Samper E, Cuthbert A, Wojcik A, Szumiel I, Bryant PE, Riches AC, Thompson A, Blasco MA, Newbold RF and Slijepcevic P: Telomere length abnormalities in mammalian radiosensitive cells. Cancer Res 61: 912-915, 2001.

23. Rubio MA, Davalos AR and Campisi J: Telomere length mediates the effects of telomerase on the cellular response to genotoxic stress. Exp Cell Res 298: 17-27, 2004.

24. Rubio MA, Kim SH and Campisi J: Reversible manipulation of telomerase expression and telomere length. Implications for the ionizing radiation response and replicative senescence of human cells. J Biol Chem 277: 28609-28617, 2002.

25. Sprung CN, Davey DS, Goh SK, Radford IR and McKay MJ: Uncoupling of telomere length and radiosensitivity in mouse lymphoma cell lines of similar genetic background. Int J Radiat Biol 83: 515-521, 2007.
26. Gomez-Millan J, Goldblatt EM, Gryaznov SM, Mendonca MS and Herbert BS: Specific telomere dysfunction induced by GRN163L increases radiation sensitivity in breast cancer cells. Int J Radiat Oncol Biol Phys 67: 897-905, 2007.

27. Ji XM, Xie CH, Fang MH, Zhou FX, Zhang WJ, Zhang MS and Zhou YF: Efficient inhibition of human telomerase activity by antisense oligonucleotides sensitizes cancer cells to radiotherapy. Acta Pharmacol Sin 27: 1185-1191, 2006.

28. Nakamura M, Masutomi K, Kyo S, Hashimoto M, Maida Y, Kanaya T, Tanaka M, Hahn WC and Inoue M: Efficient inhibition of human telomerase reverse transcriptase expression by RNA interference sensitizes cancer cells to ionizing radiation and chemotherapy. Hum Gene Ther 16: 859-868, 2005. 